\title{
Annealing behavior of alpha recoil tracks in phlogopite
}

\author{
Wanming Yuan ${ }^{\mathrm{a}, *}$, Richard A. Ketcham ${ }^{\mathrm{b}}$, Shaokai Gao ${ }^{\mathrm{c}}$, Jinquan Dong ${ }^{\mathrm{d}}$, Zenkuan Bao ${ }^{\mathrm{d}}$, Jun Deng ${ }^{\mathrm{a}}$ \\ a State Key Laboratory of Geological Processes and Mineral Resources, China University of Geosciences, Beijing, 100083, China \\ b Department of Geological Sciences, Jackson School of Geosciences, The University of Texas at Austin, Austin, TX, 78712, USA \\ ${ }^{c}$ Research Center for Eco-Environmental Sciences, Chinese Academy of Sciences, Beijing, 100085, China \\ ${ }^{\mathrm{d}}$ Laboratory of Nuclear Analysis Techniques, Institute of High Energy Physics, Chinese Academy of Sciences, Beijing, 100039, China
}

\section{A R T I C L E I N F O}

Article history:

Received 9 February 2009

Accepted 27 June 2009

Editor: D. Rickard

\section{Keywords:}

Alpha recoil tracks

Phlogopite

Annealing

\begin{abstract}
A B S T R A C T
In this study we present and interpret a new experimental data set documenting thermal annealing of alpha recoil tracks (ARTs) in phlogopite. Through improvements in experimental technique, difficulties in obtaining useable data from material with an uneven distribution of $U$ and Th were overcome. The resulting annealing pattern was well organized on an Arrhenius plot, allowing construction of a simple, 3-parameter annealing model of parallel contours of constant annealing with a linear progression. Our data and model indicate that phlogopite ARTs anneal at very low temperatures on geological time scales. At the million-year time scale, full annealing requires a temperature of only $33^{\circ} \mathrm{C}$, and we infer closure temperatures from $26-37^{\circ} \mathrm{C}$ for cooling rates of $10-100^{\circ} \mathrm{C} / \mathrm{m}$.y. Phlogopite ART analysis is thus likely to be primarily useful in relatively young $(<1 \mathrm{Ma})$ terrains featuring either recent volcanism or recent, fast exhumation. In such situations, however, it may provide unique information on the timing of the final stages of unroofing. Comparison of our results with previous studies on ART and fission-track annealing in phlogopite and biotite indicates that these two types of radiation damage anneal at disparate time and temperature conditions in biotite-series micas.
\end{abstract}

(c) 2009 Elsevier B.V. All rights reserved.

\section{Introduction}

Uranium and thorium are trace elements in natural phlogopite. Their isotopes ${ }^{238} \mathrm{U},{ }^{235} \mathrm{U}$ and ${ }^{232} \mathrm{Th}$ and their daughter products undergo radioactive decay by emitting a series of $\alpha$ particles. Several MeV of energy are released through successive $\alpha$ decays, of which the dominant portion goes into the kinetic energy of the ejected $\alpha$ particles according to the principles of momentum and energy conservation. About $2 \%$ of the energy is released as the kinetic energy of the recoil nucleus. The recoiled nuclei transfer energy to the crystal lattice of the mineral through nuclear collisions, forming a radiation damage zone that becomes observable as alpha recoil tracks (ARTs) (Fig. 1) under an optical microscope after chemical etching (Huang and Walker, 1967; Hashimoto et al., 1981; Hashemi-Nezhad and Durrani, 1981; Gögen and Wagner, 2000). The damage from an individual alpha recoil is much less severe than the massive disruption produced by fission fragments, but overall alpha damage in a mineral is much more extensive due to the large number of alpha decays relative to fission.

Previous work has suggested that the retention temperature for ARTs in biotite is about $100{ }^{\circ} \mathrm{C}$ lower than that of fission tracks (HashemiNezhad and Durrani, 1983; Saini and Nagpaul, 1979). The difference between closure temperatures for fission tracks and ARTs can potentially

\footnotetext{
* Corresponding author.

E-mail address: ywm010@yahoo.com (W. Yuan).
}

be a very useful tool for determining thermal history of geological samples which are capable of recording both types of tracks. Cooling histories can thus potentially be extended to a much lower temperature than is possible by studying fission tracks alone. Similarly, ARTs may also be useful in combination with other thermochronometers, such as apatite or zircon fission-track or (U-Th)/He, to better constrain thermal histories when considered simultaneously during inverse modeling (e.g., Ketcham, 2005).

Though previous studies have documented the time-temperature conditions required for total ART annealing in biotite (Nagpaul et al., 1974; Hashemi-Nezhad and Durrani, 1983), a more complete understanding of the partial annealing conditions for alpha recoil tracks has been elusive, likely in large part due to the very common condition of an uneven distribution of $U$ and Th within and among mica grains. After experiencing these difficulties, we developed an experimental technique to overcome this problem, allowing us to assemble a coherent data set to quantitatively characterize all stages of ART annealing in phlogopite.

\section{Experiments}

\subsection{Samples}

All phlogopite samples used in this study were collected from the same locality at the 12th crater of Hama Pond, Jingbo Lake, in the northeast of China. Although the precise sampling locality has not been 


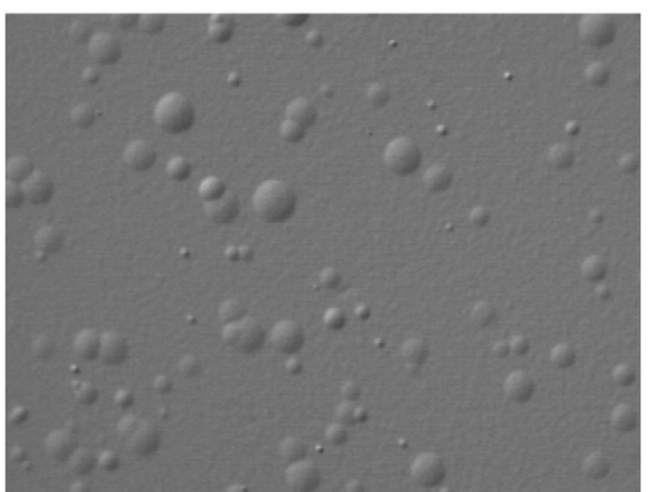

Fig. 1. Alpha recoil tracks on etching surface of phlogopite, as observed with NDIC microscopy. Field of view is $\sim 60 \mu \mathrm{m}$ wide.

dated, carbon dating of carbonized wood from trees killed in one eruptive episode for the Jingpohu volcanic group indicates an age range of 5200-5500 ka (Fan et al., 2003).

Results from an electron microprobe analysis of mica from this locality by Zhang et al. (2001) are provided in Table 1 . Stoichiometry was calculated as $\mathrm{K}_{0.9} \mathrm{Na}_{0.1}\left(\mathrm{Mg}_{1.38} \mathrm{Fe}_{0.63} \mathrm{Al}_{0.13} \mathrm{Ti}_{0.46} \mathrm{Mn}_{0.4}\left[\mathrm{Al}_{1.25} \mathrm{Si}_{2.75} \mathrm{O}_{10}\right.\right.$ $(\mathrm{OH})_{2}$ ], based on twenty-two positive charges per formula unit excluding the anion site (Rieder et al., 1998), complete occupancy of the $\mathrm{OH}$ site by hydroxyl groups and complete occupancy of the fourfold coordinated cation sites $\left({ }^{\mathrm{IV}} \mathrm{Si}+{ }^{\mathrm{IV}} \mathrm{Al}=4\right)$. The mica is principally a phlogopite $(\mathrm{Mg} /(\mathrm{Mg}+\mathrm{Fe}) \sim 0.69)$ but with significant annite and titanian biotite components.

\subsection{Annealing and measurement}

Annealing experiments were conducted using a high-temperature vacuum electric furnace with a fast re-equilibration time after sample loading. Temperature was monitored using a thermocouple in the vicinity of the sample. Temperature precision was within $1{ }^{\circ} \mathrm{C}$ at the $95 \%$ confidence level.

Two set of experiments were conducted. In the first set, different samples phlogopite were heated at $250 \pm 1{ }^{\circ} \mathrm{C}$ for various time spans, and measured individually after being fixed on different PTFE (polytetrafluoroethylene) holders using HF-resistant resinous glue.

For the second set, orthogonal marks were made on the surface of phlogopite books, and the contour of each book was made on the PTFE holder (Fig. 2). Then individual mica books were annealed at temperatures ranging from $200{ }^{\circ} \mathrm{C}$ to $450{ }^{\circ} \mathrm{C}$ in steps of $50{ }^{\circ} \mathrm{C}$, for times ranging from 1 to $1400 \mathrm{~h}$. After annealing for a given amount of time at a particular temperature, several flakes were cleaved off each book for track counting, leaving the remainders of the books available for further annealing at the same temperature. Annealing at each temperature was continued until fading was complete, and new books were utilized when the temperature was changed. The marks on the samples and PTFE holders allowed us to accurately reproduce the areas used for ART counting. This procedure bypassed any problems from inhomogeneity

Table 1

Electron microprobe analysis of biotite.

\begin{tabular}{lc}
\hline Oxide & Wt.\% \\
\hline $\mathrm{SiO}_{2}$ & 38.02 \\
$\mathrm{TiO}_{2}$ & 8.65 \\
$\mathrm{Al}_{2} \mathrm{O}_{3}$ & 16.16 \\
$\mathrm{FeO}$ & 10.43 \\
$\mathrm{MnO}$ & 0.1 \\
$\mathrm{MgO}$ & 12.82 \\
$\mathrm{Na}_{2} \mathrm{O}$ & 0.53 \\
$\mathrm{~K}_{2} \mathrm{O}$ & 8.33 \\
Total & 95.04 \\
\hline
\end{tabular}

and zoning except along the phlogopite crystallographic c-axis, of which no obvious evidence was observed in this study. It also provided an automatic normalization for vertical etching rate, as discussed below.

Measurement of ART density utilized similar techniques to those described by Gögen (1999) and Glasmacher et al. (2003). Samples were etched twice in $4 \% \mathrm{HF}$ acid at $25 \pm 1{ }^{\circ} \mathrm{C}$, each time for $10 \mathrm{~min}$, and alpha recoil tracks were counted after each etch using Nomarski differential interference contrast (NDIC) microscopy. Measurements were made using an AUTOSCAN automated microscope stage system, similar to the system used by many fission-track laboratories. A counting area $\left(1.869 * 10^{-4} \mathrm{~cm}^{2}\right)$ on each sample was selected, and returned to each time using the automated stage system. From two to five counting areas were measured for each run. All measurements were done by a single analyst.

The two density measurements at different etch times define a line on a plot of etching time versus areal track density (Gögen, 1999), the slope of which corresponds to $\rho_{v} v_{v}$, the track volume density times the vertical bulk etching velocity. To determine an absolute density as required for standard ART thermochronometry, the etching rate $v_{v}$ must be evaluated via independent means, and has been found to be quite variable from one mica book to another (Yuan et al., 2008). However, for this study we only require knowledge of density reduction rather than absolute density. Thus, under the assumption that the etching rate in a single mica book is invariant and unaffected by annealing, density reduction at any heating increment $i$ is simply obtained by dividing its slope by the slope from the unannealed experiment:

$\frac{\rho_{v, i} v_{v}}{\rho_{v, 0} v_{v}}=\frac{\rho_{v, i}}{\rho_{v, 0}}$.

Under the further simplifications of a constant counting area and only two track counts with a constant etching time interval between them, the ratio is determined simply from the number of counts at each etching step:

$\frac{\rho_{v, i}}{\rho_{v, 0}}=\frac{N_{2, i}-N_{1, i}}{N_{2,0}-N_{1,0}}$

where $N_{1, i}$ is the number of track counted in the region of interest after the first etching step for annealing conditions $i$, etc. Results from multiple measurement areas are combined by taking the mean of their normalized densities; the count data cannot be combined directly because Eq. (1) only applies to a single measurement area.

\subsection{Estimation of uncertainties}

Because track counts are typically relatively low (100's in early annealing stages to 10 's to 1 's in late ones), a Poissonian model is the most appropriate for evaluating uncertainties. Estimation of this component of error can be simplified by considering that all tracks counted after the first etching step are also counted after the second, and so the difference in track counts has Poissonian uncertainty as well; i.e. if we define $N_{2-1, i}$ as the number of additional tracks revealed between etching steps 1 and 2 for annealing experiment $i$, then it is clear that the difference $N_{2, i}-N_{1, i}=\left(N_{1, i}+N_{2-1, i}\right)-N_{1, i}=N_{2-1, i}$ has the statistical properties of an independent count. Using standard error propagation the uncertainty in the ratio from counting statistics can then be estimated as:

$$
\sigma_{\rho_{v, i} / \rho_{v, 0}}=\sqrt{\frac{N_{2-1, i}}{N_{2-1,0}^{2}}+\frac{N_{2-1, i}^{2}}{N_{2-1,0}^{3}}}
$$

In subsequent analysis of our results, it became apparent that Eq. (3) substantially underestimates of the uncertainties in our measurements. We thus posit an additional, small component of error that is constant 

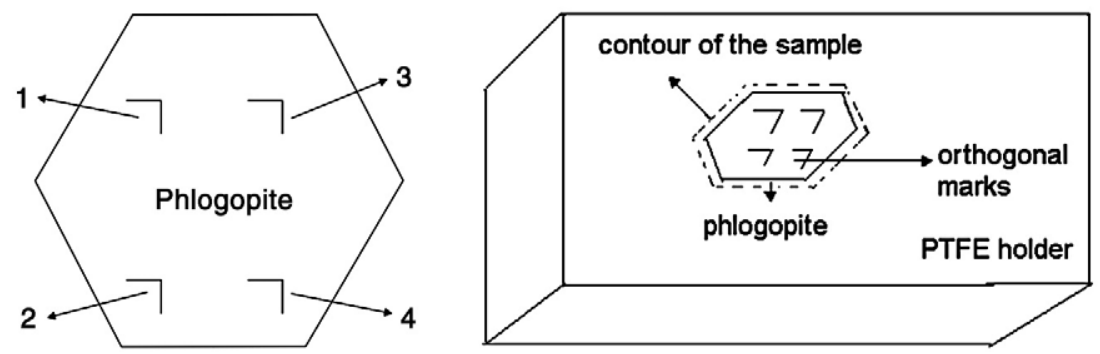

Fig. 2. Schematic figure showing experiment protocol to reproduce ART counting areas between annealing runs.

across all experiments. Possible origins of this component are discussed below.

\section{Results}

\subsection{Different kinds of ARTs}

In the annealing experiments, we found two kinds of alpha recoil tracks for which the radial growth rate is different under the same etching conditions (Fig. 3). What we term category 1 tracks represent the great majority that grow with progressive etching, but category 2 tracks quickly achieve a stable size and do not grow. One possible explanation for this phenomenon is that the tracks could have been formed by different numbers of recoils of the heavy nucleus. Similarly divergent etching behavior was also observed by Stübner et al. (2008), whose model of etch figure development suggests an alternative explanation. According to their model, etch figure depth and width increase fastest while there is still latent track below the etching surface; once the end of latent track is reached etching slows and etch figures approach a near-steady-state configuration. It is thus possible that shallow tracks truncated by the separation of mica cleavage planes during mount preparation may etch more slowly and shallowly and reach a near-steady-state diameter and depth more quickly. Yet another possibility is that category 2 features are not ARTs at all. Further study is needed to elucidate this problem. Tracks were not differentiated for ART density determinations.

\subsection{Annealing measurements}

In the first experiment group, in which different samples were used for each heating interval, the ART density varies widely across both samples and counting areas within the same sample due primarily to the uneven distribution of $U$ and Th. As a result there was no systematic relationship between track density and thermal input, as exemplified by the results shown in Table 2. For this reason, techniques were improved for the second experiment as described above.
In the second group, a base value for the track revelation rate (tracks $/ \mathrm{cm}^{2} / \mathrm{min}$ of etching) was obtained for each mica book before any heating. Measurements of the track revelation rate after each increment of heating were then normalized against this value to obtain a net density reduction $\left(\rho / \rho_{0}\right)$. Complete results are provided in Table 3. This procedure presumes that the vertical etching rate of the phlogopite remains unchanged during ART annealing. This is not an idle concern, as Parshad et al. (1978) note that the etching time necessary to maximize fission-track density measurements in phlogopite systematically increases with extent of annealing. However, the consistent and simple systematic pattern of annealing across various temperature conditions described in the next section strongly suggests that this assumption is reasonable.

The raw annealing data are shown in Fig. 4. In general, the annealing runs at each temperature define nearly parallel arrays with fairly even spacing corresponding to the constant temperature interval between runs. An exception is the $300{ }^{\circ} \mathrm{C}$ run, which appears offset leftwards compared to the sequence defined by the other experiments.

\subsection{Modeling}

To examine what form an Arrhenius-type characterization of these data should take, we followed the approach of Laslett et al. (1987) and posed the relation

$A\left(\rho / \rho_{0}\right)=\ln (t)-B / T$,

where $A$ is a transform of unknown form, $B$ is a constant, $t$ is time in seconds, and $T$ is temperature in Kelvin. A rough estimation procedure resulted in a $B$ value of 12,000 , resulting in the relation shown in Fig. 5. It is evident that the form of $A$ is close to linear, as opposed to the nearlogarithmic or power law forms often obtained for fission-track length reduction in apatite and zircon (e.g., Laslett et al. 1987; Ketcham et al. 2007; Rahn et al. 2004; Yamada et al. 2007). It bears nothing that a strictly linear relation would not be asymptotic, violating the condition $A(1)=-\infty$ cited by Laslett et al. (1987) to ensure a valid starting point and continuous solution. Failure of this condition would indicate an

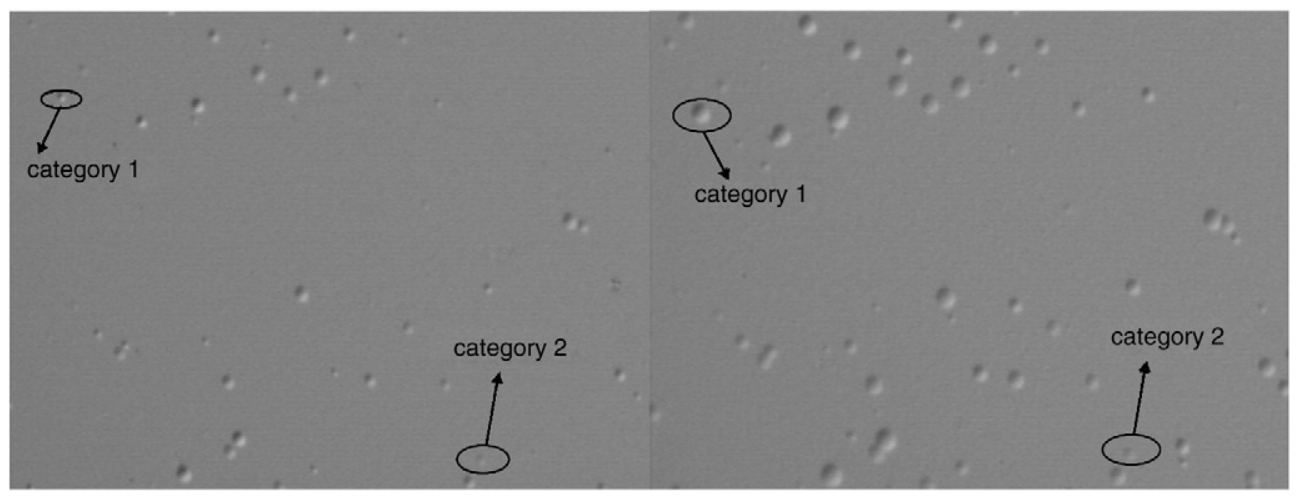

Fig. 3. Set of ARTs after sequential etching steps, showing different etching behaviors of category 1 and category 2 tracks. Each field of view is $\sim 100 \mu$ m wide. 
Table 2

Annealing results for the first experiment group $\left(250^{\circ} \mathrm{C}\right)$.

\begin{tabular}{ll}
\hline Annealing time $(\mathrm{h})$ & Track revelation rate $\left(\mathrm{min}^{-1 *} \mathrm{~cm}^{-2 *} 10^{4}\right)$ \\
\hline 4 & 0.867 \\
6 & 0.995 \\
10 & 1.005 \\
12 & 0.599 \\
18 & 0.642 \\
22 & 0.241 \\
24 & 0.508 \\
26 & 0.455 \\
28 & 0.460 \\
32 & 0.144 \\
34 & 1.050 \\
40 & 0.118 \\
45 & 0.947 \\
50 & 0.177 \\
60 & 1.187 \\
70 & 0.894 \\
86 & 0.203 \\
\hline
\end{tabular}

abrupt transition to zero annealing once one crossed to the right of the $\rho / \rho_{0}=1$ isoannealing contour on the Arrhenius diagram, which is probably unreasonable. It is possible that if we had more data at extremely low levels of annealing an asymptotic trend might become apparent, but there is no indication of it in the data we have thus far. However, even if such a transition did occur in the region above $\rho / \rho_{0}=0.9$, it would not detract from the linear trend observed in the data at higher levels of annealing, which are more the realm of interest for thermal history applications. We thus adopted a simple linear form for $A$.

The experiments done at $300{ }^{\circ} \mathrm{C}$ are systematically offset from the trend formed by the rest of the measurements at both higher and lower temperatures. The reason for this departure is unknown; possibilities include a temporary calibration problem with the furnace, or that the phlogopite book used for that run could be in some way distinct in its material properties from the others. Because of this discrepancy, these data were omitted from modeling, except for sensitivity testing purposes.

The data were fitted to a number of Arrhenius equation forms using the methods described by Ketcham et al. (1999, Appendix A). Fits to parallel linear, fanning linear, and parallel curvilinear equations were

Table 3

Annealing results for second experiment group.

\begin{tabular}{lclll}
\hline $\mathrm{T}\left({ }^{\circ} \mathrm{C}\right)$ & Annealing time $(\mathrm{h})$ & $\rho / \rho_{0}$ & $\sigma_{\rho / \rho 0} 1$ & $\sigma_{\rho / \rho 0} 2$ \\
\hline 200 & 281 & 0.911 & 0.083 & 0.087 \\
200 & 485 & 0.713 & 0.068 & 0.073 \\
200 & 1406 & 0.515 & 0.053 & 0.060 \\
250 & 29.0 & 0.888 & 0.081 & 0.085 \\
250 & 35.5 & 0.709 & 0.068 & 0.073 \\
250 & 103 & 0.515 & 0.053 & 0.060 \\
250 & 604 & 0.204 & 0.030 & 0.040 \\
250 & 859 & 0.023 & 0.009 & 0.028 \\
300 & 5.07 & 0.697 & 0.067 & 0.072 \\
300 & 10.1 & 0.571 & 0.058 & 0.064 \\
300 & 15.1 & 0.450 & 0.049 & 0.056 \\
300 & 20.2 & 0.401 & 0.045 & 0.052 \\
300 & 30.1 & 0.233 & 0.032 & 0.042 \\
300 & 40.4 & 0.128 & 0.024 & 0.036 \\
300 & 80.7 & 0.015 & 0.007 & 0.028 \\
350 & 5.07 & 0.481 & 0.051 & 0.058 \\
350 & 10.1 & 0.268 & 0.035 & 0.044 \\
350 & 15.1 & 0.185 & 0.029 & 0.039 \\
350 & 20.2 & 0.130 & 0.024 & 0.036 \\
350 & 23.2 & 0.050 & 0.014 & 0.031 \\
400 & 3.01 & 0.213 & 0.031 & 0.041 \\
400 & 8.06 & 0.020 & 0.008 & 0.028 \\
450 & 1.19 & 0.128 & 0.024 & 0.036 \\
450 & 1.76 & 0.014 & 0.007 & 0.028 \\
\hline & & & &
\end{tabular}

$\sigma_{\rho / \rho 0} 1$ : Errors calculated based on Eq. (3).

$\sigma_{\rho / \rho 0} 2$ : Errors also include constant component (0.027) across all experiments.

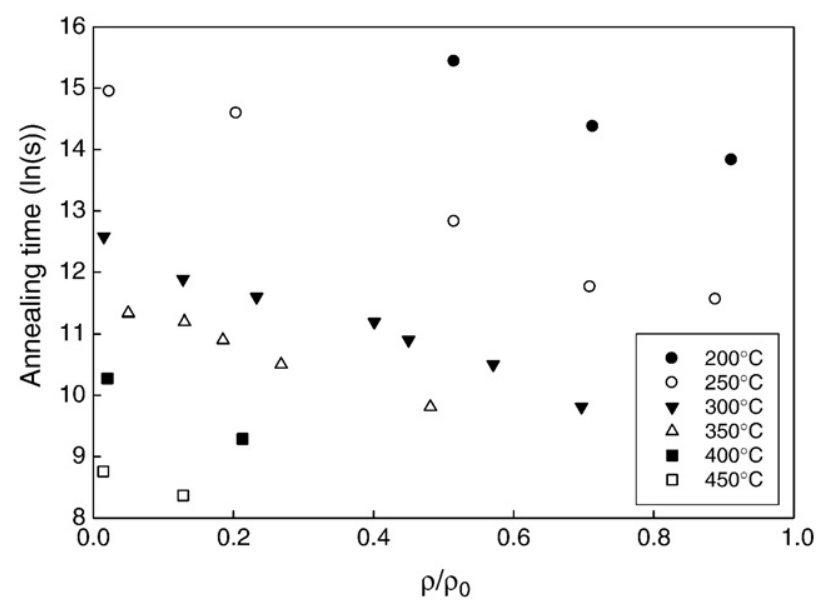

Fig. 4. ART density reduction data from second set of annealing experiments.

created. The fanning linear (e.g., Laslett et al., 1987) fits were invariably worse than the others, and because that form is more complex (and includes more fitted parameters) we will not consider it further here. The parallel linear model form is

$\rho / \rho_{0}=C_{0}+C_{1} \ln (t)+C_{2} / T$

and the parallel curvilinear model is of the form

$\rho / \rho_{0}=C_{0}+C_{1} \ln (t)+C_{2} \ln (1 / T)$.

Results of the fitting are provided in Table 4. When errors were assumed to be fully described by Eq. (3) (Table 3, column 4), the parallel curvilinear model gives a better result. However, reduced chi-squared $\left(\chi_{\nu}^{2}\right)$ values for both fits are significantly over 1 , indicating either that our equations are not proper or that there is an additional component of error that we were not able to quantify. Inspection of residuals led us to conclude that the latter was the more likely explanation, as, at least in the case of the parallel linear model, the misfit appeared uniform and unstructured. We thus posited that the unquantified error component was also uniform, and found that including an additional uncertainty in normalized density of 0.027 across all experiments (Table 3, column 5) lowered the parallel linear $\chi_{v}^{2}$ value to unity. The uncertainty was also reduced for the parallel curvilinear model, but not nearly as much, and the final $\chi_{\nu}^{2}$ value was not as low as that for the parallel linear model.

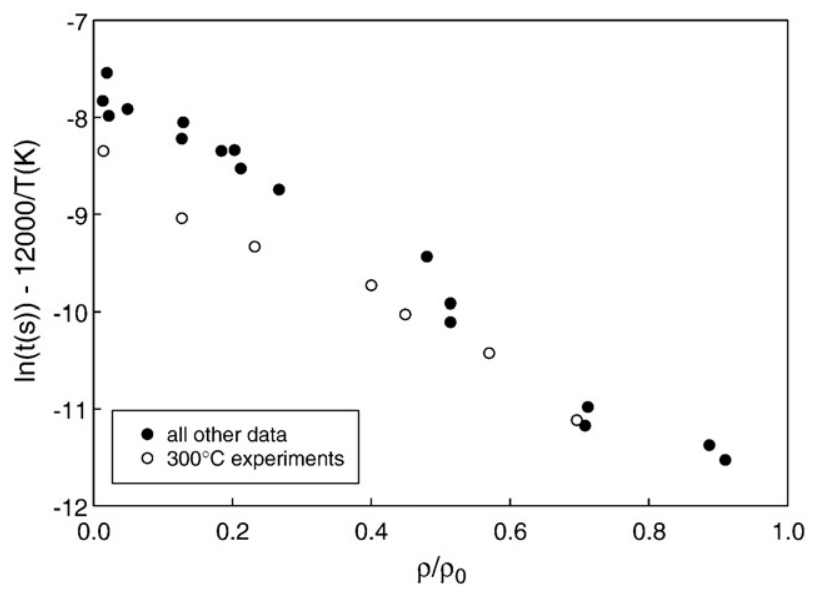

Fig. 5. Plot of annealing data against approximated Arrhenius transform function, showing roughly linear trend and departure of annealing data from $300{ }^{\circ} \mathrm{C}$ run. 
Table 4

Results of fitting model equations.

\begin{tabular}{lllclc}
\hline Type $^{\mathrm{a}}$ & Error model $^{\mathrm{b}}$ & $\chi_{\nu}^{2}$ & $C_{0}$ & $C_{1}$ & $C_{2}$ \\
\hline PL & 1 & 5.48 & 1.6338 & 0.22478 & -2637.7 \\
PC & 1 & 2.21 & -33.076 & 0.24265 & -4.6974 \\
PL & 2 & 0.99 & 1.6766 & 0.22949 & -2705.4 \\
PC & 2 & 1.14 & -33.158 & 0.23849 & -4.7177 \\
\hline
\end{tabular}

Asymmetric 95\% confidence limits for the preferred model parameters (line 3 ) are $-0.01396 /+0.29081$ for $C_{0},-0.00481 /+0.03602$ for $C_{1}$, and $-394.0 /+40.0$ for $C_{2}$.

a $\mathrm{PL}=$ Parallel linear (Eq. 4); $\mathrm{PC}=$ Parallel curvilinear (Eq. 5).

b Error model 1 based on Poissonian uncertainties only (Table 3, column 4); error model 2 includes uniform error component (Table 3, column 5).

The choice of which model form to prefer becomes more clear if the residuals are inspected (Fig. 6). The residuals with respect to density reduction and, more importantly, time show no structure for the parallel linear model. The parallel curvilinear model residuals are strongly positive with increasing time, suggesting that it would significantly underestimate density reduction on geological time scales.

The residual plots belie the expectation of error solely based upon counting statistics, which tends to most heavily weight experiments at advanced stages of annealing, for which the uncertainties are small in an absolute sense, even if they are large relative to their respective density measurements. One possible source of roughly evenly-distributed uncertainty may lie in detection and counting of small or weaklyexpressed ARTs, which may occur at all stages of annealing because of partial impingement into the mica flake from above or below. Another possible source of uncertainty is the divergent behavior of category 1 and category 2 tracks, which may indicate that they are entirely different features or represent a feature of annealing and etching that we do not yet fully understand. If, for example, category 2 tracks are not ARTs but are instead a rare feature that is not annealed at the conditions of these experiments, their occurrence would be a uniformly distributed component of error.

In all cases, models fit with the $300{ }^{\circ} \mathrm{C}$ data included have much higher $\chi_{\nu}^{2}$ values but make similar geological time-scale predictions. We therefore infer that there is no penalty in omitting them. Possible explanations for these data are a temporary furnace calibration error or an unusual mica book that etched more slowly as heating progressed and thus violated the assumption of a constant etch rate, artificially lowering track densities compared to other books.

\section{Discussion}

The simple nature of the parallel linear annealing equation and unstructured residuals strongly suggests that geological time-scale behavior can be reasonably inferred from the data collected in this study. Fig. 7 shows example contours of constant annealing corresponding to the lowest and highest annealing levels measured. It is evident that phlogopite ARTs anneal at very low temperatures in geological settings, and are thus prone to erasure. At the million-year time scale, full annealing requires a temperature of only $33^{\circ} \mathrm{C}$. Even brief exposure to wildfires (600-700 ${ }^{\circ} \mathrm{C}$; Reiners et al., 2007) would also be expected to result in full erasure. It is thus apparent that phlogopite ART thermochronology will only be useful in relatively young $(<1 \mathrm{Ma})$ terrains that have undergone little to no burial, but are insulated against possible extreme transient events. This finding is broadly compatible with the 200-300 ka ages obtained by Gögen and Wagner (2000) from ARTs in Quaternary volcanics in the Eifel region of Germany. We also note that that the curvilinear model form predicts full erasure after only 10,000 years at $21^{\circ} \mathrm{C}$, which is inconsistent with the observation that these features are preserved at the $100 \mathrm{ka}$ time scale.

At shorter time scales, phlogopite ARTs are stable to somewhat higher temperatures in stable settings. At the $1 \mathrm{ka}$ time scale erasure is negligible below $\sim 60^{\circ} \mathrm{C}$, and some tracks persist up to $100{ }^{\circ} \mathrm{C}$. Phlogopite ARTs can thus potentially be a useful and sensitive low-temperature constraint for some thermal reconstructions, and may help pin down the final stages of unroofing in recently exposed or still-active areas.

For the annealing model we calculated a closure temperature of $26{ }^{\circ} \mathrm{C}$ given a $10{ }^{\circ} \mathrm{C} / \mathrm{m}$.y. cooling rate, using an updated version of the FTINDEX program (Ehlers et al. 2005). This value is somewhat artificially bounded by the condition of linear cooling to an assumed earth-surface
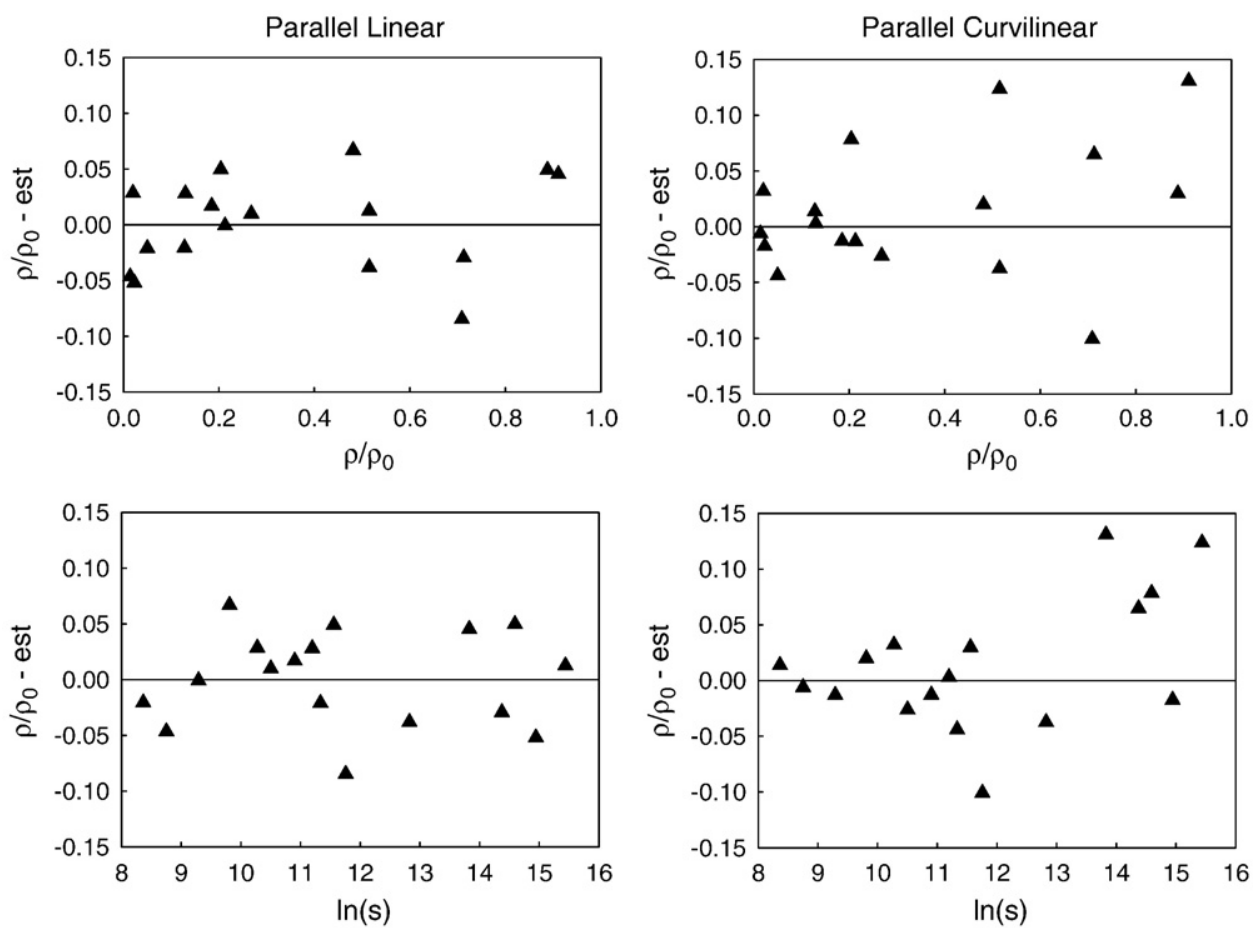

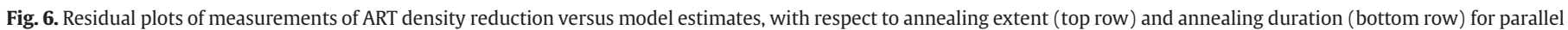
linear (left column) and curvilinear (right column) equation forms. 


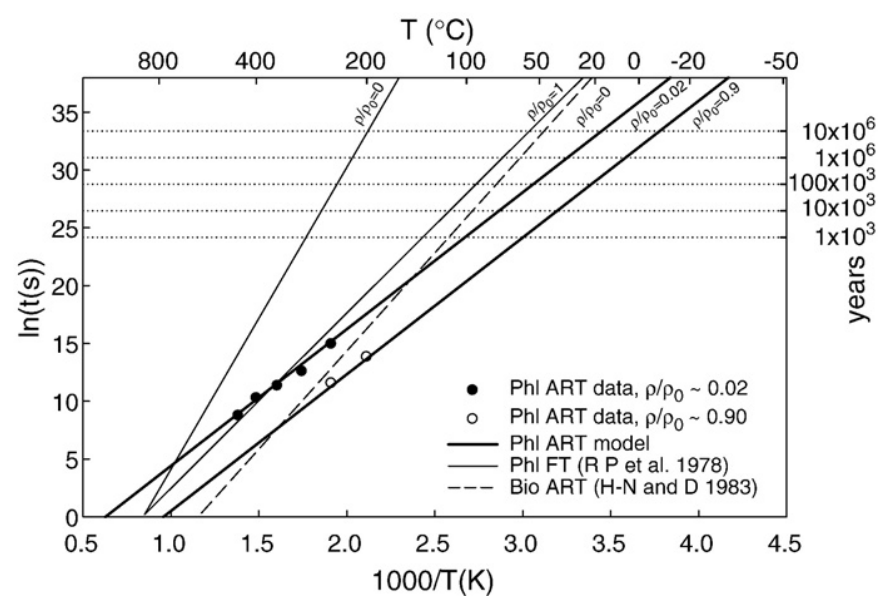

Fig. 7. Isoannealing contours for phlogopite ARTs (this study) and fission tracks (Parshad et al. 1978) and biotite ARTs (Hashemi-Nezhad and Durrani, 1983).

temperature of $20^{\circ} \mathrm{C}$ as implemented by the program. It should also be borne in mind that the concept of a closure temperature defined by a cooling rate with a millions-of-years time scale is not necessarily well suited for describing a system principally operational on the thousandsof-years time scale. At $100{ }^{\circ} \mathrm{C} / \mathrm{m}$.y. cooling the closure temperature is $37^{\circ} \mathrm{C}$.

The total annealing contour for ARTs in biotite determined by Hashemi-Nezhad and Durrani (1983) is also shown in Fig. 7. Their results traverse the same region of time-temperature space as the experiments in this study, but define a substantially different trend, implying less resistance to annealing at laboratory time scales but more on geological ones. Hashemi-Nezhad and Durrani (1983) do not provide any chemical data for their biotite, so it is unknown how compositionally similar or dissimilar their material was to that used in this study, and by extension the extent to which the different annealing behaviors may be traced to composition. It is possible that some of the divergence may be attributable to differences in experimental detail. Their approach was to find the approximate time necessary to erase all ARTs at various temperatures via a sequential series of heating steps, which is not as robust a method as the one utilized here, which accounts for inhomogeneity and derives information from intermediate stages of annealing. In addition, the NDIC microscopy used in this study is much clearer and more reliable than the analytical methods available at the time of their work.

As previously mentioned, results reported by Saini and Nagpaul (1979) indicate that fission tracks in biotite require temperatures on the order of $100{ }^{\circ} \mathrm{C}$ higher to anneal than ARTs. Although no chemical data are provided, it is unlikely that compositional factors would upset the overall picture of relative annealing resistance between ARTs and fission tracks in biotite.

Also plotted on Fig. 7 are approximate $0 \%$ and 100\% annealing contours for fission tracks in phlogopite reported by Parshad et al. (1978). As with biotite, annealing of alpha recoil tracks in phlogopite requires significantly less thermal input than required for fission tracks.

This may contrast with behavior observed in some other minerals. Garver and Kamp (2002) demonstrate that alpha damage in zircon as inferred from color changes required higher temperatures to fade than fission-track annealing, although it is not clear whether color changes are driven by damage from the alpha particle or the recoil nucleus, or what aspect of this damage is responsible for color change. Similarly, Rahn et al. (2004) attribute a decrease in fission-track annealing resistance on geological time scales to accumulation of alpha-related damage, which by extension must itself be at least somewhat more resistant to annealing to have this effect. Again, however, it is not known what aspect of alpha damage is responsible for altering annealing resistance. At the other end of the time scale, however, Braddy et al. (1975) report that zircon solubility, which is believed to be heavily influenced by alpha damage, can be altered by brief heating at laboratory time scales while leaving fission-track density unchanged, suggesting that there may be a kinetic crossover at different time scales (e.g., Reiners, 2009). Thus, it seems probable that the relative resistance to annealing of alpha recoil tracks and fission tracks may vary in different mineral groups and at different time scales; for example, it may be that sheet silicates are innately more amenable to ART annealing.

The issue of relative annealing resistance is also of current interest due to the recent recognition that radiation damage can affect helium diffusivity in apatite (Shuster et al. 2006). Shuster and Farley (2009) demonstrate that the diffusivity-altering damage anneals at laboratory conditions corresponding closely to those required for fission-track annealing in apatite. Flowers et al. (2009) show that a helium diffusivity model based on fission-track annealing can explain a number of apparent inconsistencies in some apatite fission-track and (U-Th)/He thermochronology studies. However, their favored model remains that alpha damage exerts the primary control on diffusivity, owing to its orders-of-magnitude greater abundance and the expected alpha damage contribution of thorium, which contributes negligible fission damage. It is clear that understanding the nature and annealing conditions of these two types of damage are crucial for determining helium diffusivity and thus closure temperature of the (U-Th)/He system in any case where damage predating helium retention may persist.

The linear, non-asymptotic nature of the relationship between density reduction, log-time, and inverse temperature seen in Fig. 4 is an unexpected and intriguing departure from the annealing behavior of fission tracks observed in apatite and zircon. Insofar as the radiation damage from alpha recoil is attributed to hard-body nuclear collisions rather than an ionization spike (Huang and Walker, 1967) it is reasonable to infer that this change in annealing behavior may reflect a fundamental difference in the nature of the damage, and possibly the annealing mechanism itself.

\section{Conclusions}

This study constitutes the first reported complete, quantitative characterization of the thermal annealing behavior of alpha recoil tracks in phlogopite. With careful attention to experimental detail to account for inhomogeneity in $U$ and $T h$ and possibly etching characteristics, it was possible to generate a consistent and coherent data set documenting ART density reduction as a function of time and temperature. The resulting annealing model indicates that phlogopite ARTs anneal at quite low temperatures over geological time scales, and thus this technique is probably only useful for dating young ( $<1 \mathrm{Ma}$ ) events. However, within this realm it has the capability to provide perhaps unique thermochronological information, such as dating the final stages of recent exhumation.

\section{Acknowledgments}

This work was supported by the Natural Science Foundation of China (Nos. 40872141, 10175076, 40072068 and 10475093), the National Basic Research Program of China (No. 2009CB421006) and the 111 program (No. B07011). The authors would like to acknowledge Professor Wang Shicheng very much for her meaningful suggestions on the technique of the experiment. A previous version of this paper was greatly improved thanks to comments from S. Guedes.

\section{References}

Braddy, D., Hutcheon, I.D., Price, P.B., 1975. Crystal chemistry of Pu and U and concordant fission track ages of lunar zircoms and whitlockite (abstract). In Lunar Science VI, p. 77-79. The Lunar Science Institute, Houston.

Ehlers, T.A., Chaudhri, T., Kumar, S., Fuller, C.W., Willett, S.D., Ketcham, R.A., Belton, D.X Kohn, B.P., Gleadow, A.J.W., Dunai, T.J., Fu, F.Q., 2005. Computational tools for lowtemperature thermochronometer interpretation. Reviews in Mineralogy and Geochemistry 58, 589-562. 
Fan, Q.-C., Sun, Q., Li, N., Yin, J.-H., Chen, H.-Z., Gao, F., Zhang, X.-J., 2003. The section of airfall clastic rock of Holocene volcano in Jingpohu region and its eruptive history in Chinese with English abstract Seismology and Geology 25, 3-11.

Flowers, R.M., Ketcham, R.A., Shuster, D.L., Farley, K.A., 2009. Apatite (U-Th)/He thermochronometry using a radiation damage accumulation and annealing model. Geochimica et Cosmochimica Acta 73 (8), 2347-2365.

Garver, J.I., Kamp, P.J.J., 2002. Integration of ziron color and zircon fission-track zonation patterns in orogenic belts: application to the Southern Alps, New England. Tectonophysics 349, 203-219.

Glasmacher, U.A., Lang, M, Klemme, S., Moine, B., Barbero, L, Neumann, R., Wagner, G.A. 2003. Alpha-recoil tracks in natural dark mica: dating geological samples by optical and scanning force microscopy. Nuclear Instruments and Methods in Physics Research B 209, 351-356.

Gögen, K., 1999. The alpha-recoil -track dating method: theoretical and experimental development and dating of mica. Dissertation Thesis, Rupertus Carola University of Heidelberg.

Gögen, K., Wagner, G.A., 2000. Alpha-recoil track dating of Quaternary volcanics. Chemical Geology 166, 127-137.

Hashemi-Nezhad, S.R., Durrani, S.A., 1981. Registration of alpha-recoil tracks in mica: the prospects for alpha-recoil dating method. Nuclear Tracks 5 (1/2), 189-205.

Hashemi-Nezhad, S.R., Durrani, S.A., 1983. Annealing behaviour of alpha-recoil tracks in biotite mica: implications for alpha-recoil dating method. Nuclear Tracks 7 (3), 141-146.

Hashimoto, T., Sugiyama, H., Sotobayashi, T., 1981. Alpha-recoil track formation on muscovite and measurement of recoil-range using ${ }^{252} \mathrm{Cf}$-sources. Nuclear Tracks 4 (4), 263-269.

Huang, W.H., Walker, R.M., 1967. Fossil alpha-particle recoil tracks: a new method of age determination. Science 155 (3766), 1103-1106.

Ketcham, R.A., 2005. Forward and inverse modeling of low-temperature thermochronometry data. Reviews in Mineralogy and Geochemistry 58, 275-314.

Ketcham, R.A., Donelick, R.A., Carlson, W.D., 1999. Variability of apatite fission-track annealing kinetics III: extrapolation to geological time scales. American Mineralogist 84, 1235-1255.

Ketcham, R.A., Carter, A.C., Donelick, R.A., Barbarand, J., Hurford, A.J., 2007. Improved modeling of fission-track annealing in apatite. American Mineralogist 92, 799-810.

Laslett, G.M., Green, P.F., Duddy, I.R., Gleadow, A.J.W., 1987. Thermal annealing of fission tracks in apatite 2. A quantitative analysis. Chemical Geology (Isotope Geoscience Section) 65, 1-13.
Nagpaul, K.K., Mehta, P., Gupta, M.L., 1974. Annealing studies of radiation damage in biotite, apatite and sphene, and correction of fission track ages. Pure and Applied Geophysics 112, 131-139.

Parshad, R., Saini, H.S., Nagpaul, K.K., 1978. Fission track etching and annealing phenomenon in phlogopite and their applications. Canadian Journal of Earth Science 15 (12), 1924-1929.

Rahn, M.K., Brandon, M.T., Batt, G.E., Garver, J.I., 2004. A zero-damage model for fissiontrack annealing in zircon. American Mineralogist 89 (4), 473-484.

Reiners, P.W., Thompson, S.N., McPhillips, D., Donelick, R.A., Roering, J.J., 2007. Wildfire thermochronology and the fate and transport of apatite in hillslope and fluvial environments. Journal of Geophysical Research 112, F04001. doi:10.1029/2007JF000759.

Reiners, P.W., 2009. Nonmonotonic thermal histories and contrasting kinetics of multiple thermochronometers. Geochimica et Cosmochimica Acta 73 (12), 3612-3629.

Rieder, M., et al., 1998. Nomenclature of the micas. Canadian Mineralogist 36, 905-912.

Saini, H.S., Nagpaul, K.K., 1979. Annealing characteristics of fission tracks in minerals and their applications to earth sciences. International Journal of Applied Radiation and Isotopes 30, 213-231.

Shuster, D.L., Flowers, R.M., Farley, K.A., 2006. The influence of natural radiation damage on helium diffusion kinetics in apatite. Earth and Planetary Science Letters 249, 148-161.

Shuster, D.L., Farley, K.A., 2009. The influence of artificial radiation damage and thermal annealing on helium diffusion kinetics in apatite. Geochimica et Cosmochimica Acta 73, 183-196.

Stübner, K., Jonckheere, R., Ratschbacher, L., 2008. A Monte Carlo simulation of etch pit evolution in a Kossel lattice with reference to the revelation of nuclear tracks and dislocations. Geochimica et Cosmochimica Acta 72, 3184-3199.

Yamada, R., Murakami, M., Tagami, T., 2007. Statistical modeling of annealing kinetics of fission tracks in zircon; reassessment of laboratory experiments. Chemical Geology 236, 75-91.

Yuan, W., Gao, S., Dong, J., Bao, Z., Jia, X., 2008. The etching behavior of alpha-recoil tracks in phlogopite. Radiation Measurements 43, S353-S356.

Zhang, Z., et al., 2001. Discovery of a special type of leucite tephrite in Jingpohu region of Heilongjiang province and its significance. Chinese Journal of Geology 33 (1), 23-35. 